\title{
A ARTE DE PARTEJ AR: EXPERIÊNCIA DE CUIDADO DAS PARTEIRAS TRADICIONAIS DE ENVIRA/AM
}

\author{
The art of attend the birth: experience in care of \\ traditional midwives at Envira/ AM \\ El arte de los partos: experiencia en atención de las parteras \\ tradicionales de Envira/ AM
}

\author{
Keyla Cristiane do Nascimento ${ }^{1}$ \\ Hélio José do Nascimento Júnior ${ }^{4}$
}

Evanguelia Kotzias Atherino dos Santos²

Alacoque Lorenzini Erdmann ${ }^{3}$

\section{RESUMO}

Trata-se de um estudo exploratório-descritivo de caráter qualitativo, que retrata as parteiras tradicionais de Envira, município do estado do Amazonas, onde $80 \%$ dos partos são feitos por elas. Objetiva caracterizar a experiência de cuidado no partejar dessas parteiras. Participaram do estudo 29 parteiras. Para a coleta de dados, optou-se por entrevistas gravadas. As informações foram analisadas de acordo com o método de análise de conteúdo. Seis categorias foram evidenciadas: parteiras de Envira quem são?; ofício de partejar; partejar - quanto vale esse "dom"; problemas enfrentados pela parteira; problemas frequentemente encontrados pelas parteiras na gestação/parto; e relação com o serviço de saúde. Conclui-se afirmando que há um longo caminho a percorrer na reversão dos quadros de doenças, pobreza e abandono, um caminho no qual as parteiras treinadas poderão desempenhar importante papel, na medida em que atingem muitas mulheres, configurando-se como multiplicadores concretos de conhecimentos.

Palavras-chave: Enfermagem. Saúde da Mulher. Parto Domiciliar. Políticas Públicas.

\begin{abstract}
This is a explorative-descriptive study with a qualitative character, that portrait the traditional midwives of Envira, city of the state of Amazonas, where $80 \%$ of the childbirths are made by them. The objective is to characterize the experience of care when they help to give birth, these midwives. 29 midwives took part of the study. The data were colleted from recorded interviews. The information were analyzed in accordance with analysis of content. Six categories were highlighted: Envira midwives - who are they: occupation when attending the birth; attend the birth - how much worth this "gift"; problems faced by midwives; problems frequently found by the midwives in the gestation/childbirth; and relationship with the health service. The conclusion says that there is a long way to go in reversing the tables of diseases, poverty and abandonment. A way in which the trained midwives will play an important role affecting many women, setting up as concrete multipliers of knowledge.
\end{abstract}

Keywords: Nursing. Women's health. Home Childbirth. Public politics.

\section{Resumen}

Se trata de un estudio exploratorio-descriptivo de carácter cualitativo, que retrata las parteras tradicionales de Envira, municipio del estado de Amazonas, donde $80 \%$ de los partos son realizados por ellas. Su objetivo es caracterizar la experiencia del cuidado en el parto. Los participantes del estudio fueron 29 parteras. Para la recopilación de datos, fue elegida las entrevistas grabadas. La información se analizó en función de análisis de contenido. Seis categorías se destacaron: parteras de Envira - que son: ocupación de ayudar en el parto: cuánto vale este "don"; problemas que enfrentan las parteras; problemas frecuentes de las parteras durante el embarazo o el parto, y la relación con los servicios de salud. Se concluye diciendo que hay un largo camino por seguir para reverter los cuadros de enfermedades, pobreza y abandono. Una manera en que las parteras capacitadas pueden desempeñar papel importante, en la medida en que afectan a muchas mujeres, estableciendo como multiplicadores concretos del conocimiento.

Palabras clave: Atención de enfermería. Promoción de la salud. Enfermedad crónica.

${ }^{1}$ Enfermeira. Mestre em Enfermagem. Doutoranda do Programa de Pós-Graduação em Enfermagem (PEN) da Universidade Federal de Santa Catarina (UFSC). Bolsista da Coordenação de Aperfeiçoamento de Pessoal de Nível Superior (CAPES). Membro do Grupo de Estudos e Pesquisas em Administração de Enfermagem e Saúde (GEPADES) na UFSC. Brasil. E-mail: keyla_nascimento@hotmail.com, ${ }^{2}$ Enfermeira. Doutora em Enfermagem. Professora do Departamento de Enfermagem e PEN/UFSC. Chefe do Departamento de Enfermagem da UFSC - Brasil. evanguelia@nfr.ufsc.br, ${ }^{3}$ Enfermeira. Doutora em Filosofia da Enfermagem. Professora Titular do Departamento de Enfermagem e PEN/UFSC. Pesquisadora do 1A CNPq. Coordenadora do GEPADES. Brasil. E-mail: alacoque@newsite.com.br, ${ }^{4}$ Acadêmico da $3{ }^{a}$. Fase de Enfermagem da UFSC. Bolsista IC/CNPq. Brasil. E-mail: helinho figueira@yahoo.com.br, ${ }^{5}$ Enfermeira. Mestre em Saúde Pública. Professora da Universidade Federal do Pará. Doutoranda do Programa de PósGraduação em Enfermagem (PEN) da Universidade Federal de Santa Catarina (UFSC) - Modalidade DINTER. Membro do Grupo de Estudos e Pesquisas em Administração de Enfermagem e Saúde (GEPADES) na UFSC e do grupo de Estudos e Pesquisa Educação, Política e Tecnologia em Enfermagem da Amazônia. Brasil. E-mail: jaciracarvalho@click21.com.br. 


\section{INTRODUÇÃO}

Estamos vivendo, nos últimos tempos, um período de transição importante nos modelos de atenção obstétrica, no qual são retomados valores que transcendem aspectos essencialmente científicos e tecnológicos. Isso se deve, inquestionavelmente, à constatação de que, apesar de todos os esforços empreendidos e dos avanços incorporados, a qualidade de atenção obstétrica, especialmente em nosso país, continua muito aquém do ideal preconizado. No cerne dessa problemática, encontram-se a medicalização exacerbada, a utilização de tecnologias do parto de modo inapropriado e um aumento significativo das taxas de cesariana.

Diante deste quadro, formuladores de políticas públicas, gestores e entidades representativas, num esforço colaborativo, têm delineado diferentes estratégias no sentido de reverter a situação. Entre as inúmeras estratégias adotadas pelo Ministério da Saúde, por meio da Área Técnica da Saúde da Mulher, destaca-se a implementação do Programa Trabalhando com Parteiras Tradicionais para a redução da morbimortalidade materna e neonatal, desde 0 ano de 2000. Este programa tem como objetivo principal "assegurar a melhoria da gestação, do parto, do nascimento e do puerpério assistidos por parteiras tradicionais, na perspectiva dos direitos de cidadania e da equidade" $"$.

Para tanto, busca sensibilizar gestores e profissionais de saúde no sentido de reconhecerem as parteiras tradicionais como parceiras na atenção à saúde da comunidade e no desenvolvimento de ações para valorizar, apoiar, qualificar e articular o seu trabalho ao SUS - Sistema Único de Saúde. Vale ressaltar que o programa foi elaborado considerando-se a diversidade socioeconômica, cultural e geográfica do País.

Embora seja uma das profissões mais antigas do mundo, registros históricos mostram que os primeiros cursos direcionados para formação de parteiras no Brasil, datam de $1832^{2}$.

Parteira tradicional é aquela que presta assistência ao parto domiciliar e que é reconhecida pela comunidade como parteira. Originalmente adquire suas aptidões fazendo partos por conta própria ou após aprender o ofício com outras parteiras. A formação de quase todas foi na prática, no embate com a falta de assistência às mulheres, estimuladas pelo desejo de servir, pela curiosidade, pela necessidade de trabalhar. Parteiras fazem mais do que partos, são conselheiras, curadoras da família e dos necessitados. Pessoas que detêm saber essencial na sobrevivência de suas comunidades ${ }^{3}$.

Desde o período imperial, quando da vinda da corte ao Brasil, há notícia de tentativas de regulamentação e controle das artes de parturição. Porém, tais tentativas não tiveram muito êxito, ficando por conta da época da República, principalmente nas primeiras décadas deste século, tais regulamentações. 0 processo de profissionalização das parteiras faz deste movimento um movimento histórico ${ }^{4}$. 0 modelo de assistência obstétrica, caracterizada por um alto grau de medicalização e de abuso de práticas invasivas, surgiu a partir do modelo intervencionista e curativo de assistência instalado no Brasil, principalmente após a década de $60^{5}$.

Muitas dessas intervenções e mudanças não têm provocado melhoria na assistência obstétrica e na condição de saúde materno-infantil; pelo contrário, evidências científicas vêm revelando que algumas são prejudiciais para a mãe e o filho ${ }^{5}$.

A transferência do parto do ambiente doméstico para o contexto hospitalar foi acompanhada por uma série de transformações no processo de parturição. A parturiente e 0 feto perdem o papel de protagonistas nesse processo, assumindo uma posição passiva, enquanto os profissionais passam a tomar o controle sobre o nascimento, realizando uma série de intervenções e modificando as práticas obstétricas. Foi a partir desse processo que foram criados cursos para parteiras, formando as parteiras medicalizadas ${ }^{6}$, consagradas pelo próprio Estado.

No entanto, essas parteiras qualificadas acabam assumindo papéis nas maternidades, sempre hierarquicamente inferiores aos outros profissionais, diferentemente no parto domiciliar, quando são responsáveis por todo o processo. Os saberes e as técnicas mantidas no período anterior à medicalização dão lugar a métodos mais assépticos e higiênicos e, junto com isso, toda a desqualificação das crendices populares.

Contudo, tal processo não ocorre de forma tão tranquila quanto parece. Surgiram disputas simbólicas em vários níveis, inclusive entre mulheres que de certo modo compartilhavam de uma mesma denominação. As disputas não ocorrem somente entre parteiras diplomadas ou não. As primeiras precisam buscar, nas maternidades, seu espaço, pois são consideradas auxiliares obstétricas. Sabe-se que o avanço dos instrumentos cirúrgicos foi historicamente usado como forma de evitar que mulheres continuassem desempenhando seu ofício: assim, somente médicos poderiam usar fórceps, dar pontos após a episiotomia, realizar cesarianas. Uma hierarquia estabelecida a partir de detalhes técnicos estava sendo criada: os partos difíceis e arriscados eram reservados aos homens, os partos normais, às mulheres ${ }^{6}$.

Segundo pesquisa nacional sobre demografia e saúde PNDS, realizada em 1996, a região Nor te é a que tem menor índice de parto hospitalar: 81,9\%, sendo seguida pela região Nordeste $83,4 \%$. A região Sul, com maior índice, chegam a $97,4 \%$ os partos realizados nos hospitais. Esses dados refletem as diferentes condições de acesso e organização dos serviços em cada região ${ }^{7}$. Nas regiões Norte e Amazônica, ocorrem o maior número de partos domiciliares, o que é justificado pela insuficiente rede de serviços de saúde aliada às condições geográficas que dificultam o acesso, na maior parte das vezes apenas fluvial.

№ Brasil, são feitos aproximadamente 2,6 milhões de partos anuais. Desse total, $24 \%$ são cirúrgicos ${ }^{7}$. Para coibir 0 alto índice de cesariana no País, o Ministério da Saúde lançou, em 
1998, uma portaria que determina controle rigoroso sobre o pagamento de no máximo $50 \%$ de cesarianas sobre o total de partos realizados pelo SUS. A medida conseguiu reduzir para $30 \%$ o número de cesáreas realizadas na rede pública - segundo dados da Rede Nacional Feminista de Saúde e Direito Reprodutivo ${ }^{7}$.

As parteiras são responsáveis por 450 mil partos todos os anos, trazendo ao mundo $18 \%$ das crianças nascidas no Brasil. São 45 mil mulheres só nas regiões Norte e Nordeste. Dessas, seis mil estão organizadas em rede. Segundo dados da Rede Nacional de Parteiras, estimam-se ainda que existam 60 mil parteiras tradicionais. 0 Brasil ainda apresenta um coeficiente próximo de 110 mortes maternas por 100 mil nascidos vivos. Elas correspondem a $6 \%$ dos óbitos de mulheres com idade entre 10 e 49 anos $^{8}$.

Uma das prioridades do Ministério da Saúde em parceria com o grupo Curumim é melhorar a atenção à gestação, ao parto, ao puerpério e ao recém-nascido 9 . Para isso, precisa melhorar a assistência às mulheres das áreas rurais, ribeirinhas e de lugares mais distantes, sendo a região Norte uma das áreas a serem priorizadas, pois os partos geralmente são domiciliares, realizados por parteiras tradicionais, muitas vezes em condições precárias, sem nenhum preparo e supervisão do sistema de saúde dos municípios.

Essa pesquisa, retratando quem são as parteiras tradicionais de Envira, AM, teve como objetivo caracterizar a experiência de cuidado no partejar das parteiras tradicionais. Surgiu a partir do trabalho realizado neste município, onde quase $80 \%$ dos partos são feitos por elas, sendo que as gestantes muitas vezes possuem péssimas condições de moradia e as parteiras não possuem materiais esterilizados nem condições para realização adequada dos partos, na maioria das vezes.

\section{METODOLOGIA}

Trata-se de um estudo tipo exploratório-descritivo de caráter qualitativo que busca caracterizar a experiência de cuidado no partejar das parteiras tradicionais do município de Envira.

Local do estudo: 0 município de Envira integra, segundo a divisão territorial do estado, a $4^{\mathrm{a}}$ Microrregião denominada Vale do Juruá, localizada a sudoeste do Amazonas. A sede do município situa-se à margem direita do Rio Tarauacá, distando de Manaus $1.218 \mathrm{Km}$ em linha reta e $3.496 \mathrm{Km}$ por via fluvial. 0 município tem uma área territorial de $12.909 \mathrm{Km}^{2}$, ocupando 0,82\% da área total do estado do Amazonas.

As características de relevo, vegetação e hidrografia peculiar à região Amazônica impedem o acesso por via rodoviária ao município, sendo, portanto, o acesso por via fluvial através do rio Tarauacá, e aéreo através de uma pista para pequenas aeronaves, visando promover a ligação de Envira com os municípios vizinhos e demais partes do país.

As atividades econômicas do município de Envira estão representadas basicamente pela agricultura cuja importância vem crescendo com a instalação de novas culturas como a do café, arroz, milho e feijão por meio dos incentivos do Programa $3^{\circ}$ Ciclo do Governo do Estado do Amazonas, no final da década de 90.

Sujeitos do estudo: Participaram do estudo 29 parteiras, sendo 10 residentes na área urbana da cidade e 19 residentes na área rural. As participantes foram convidadas ao estudo após serem informadas sobre o objetivo deste, bem como sobre o caráter opcional da participação, da confidencialidade dos dados e de manifestarem sua aquiescência no Termo de Consentimento Livre e Esclarecido. Durante o processo de coleta e na utilização dos dados, manteve-se respeito aos aspectos éticos, garantindo impessoalidade e sigilo da identidade, sendo realizada substituição dos nomes dos sujeitos do estudo por codificações. Assim, foram atendidos os requerimentos previstos pela resolução nº 196/96 do Conselho Nacional de Saúde ${ }^{10}$.

Coleta dos dados: Para a coleta de dados, realizamos entrevistas mediante emprego de formulário constituído de perguntas fechadas para levantar os dados sociodemográficos, tais como idade, estado civil, escolaridade e perguntas abertas pertinentes ao objeto de estudo, tais como: "como você aprendeu a fazer parto?", "quais as principais dificuldades que você enfrenta como parteira", entre outras.

Análise dos dados: A análise dos dados foi efetuada mediante leituras reflexivas, seguidas de organização e interpretação das falas. No que tange à fase de categorização dos dados, as informações foram analisadas segundo a metodologia de análise de conteúdo ${ }^{11}$. As descrições fornecidas pelas parteiras permitiram evidenciar seis categorias essenciais: parteiras de Envira - quem são?; o ofício de partejar; partejar - quanto vale esse "dom"; problemas enfrentados pela parteira; problemas frequentemente encontrados pelas parteiras na gestação/parto; e relação com o serviço de saúde.

\section{RESULTADOS E DISCUSSÃO}

CATEGORIA 1 - Parteiras de Envira - quem são ? As parteiras do município de Envira estão distribuídas entre as quase 100 comunidades ribeirinhas do interior. Na área urbana, atuam cerca de 12 mulheres, e na zona rural, por volta de 40 mulheres.

A parteira tradicional naquela localidade é uma mulher de meia-idade (73,5\% das mulheres tem mais de 46 anos), analfabeta ( $55,9 \%$ não sabem ler ou escrever) e/ou com baixa escolaridade (41,2\%). A maioria delas é casada $(55,9 \%)$ ou vive consensualmente com o companheiro (20,6\%). As relações com os maridos nem sempre são tranquilas. Como diz uma Hortênsia':

[...] com 20 anos fiquei com o primeiro marido que me abandonou quando eu estava com 20 dias de resguardo.

Em relação à identificação econômica, outra característica observada nas parteiras tradicionais de Envira relaciona-se à pobreza. Geralmente são trabalhadoras rurais $(58,8 \%)$, com 
baixo poder aquisitivo, quando $41,2 \%$ das parteiras recebem até um salário mínimo. Dez parteiras da zona rural não souberam responder ao questionamento, pois trabalham geralmente produzindo farinha, que trocam por mantimentos, não recebendo o dinheiro; além disso, é função masculina a venda de farinha e o uso do dinheiro.

CATEGORIA 2 - 0 ofício de partejar: Na maioria das vezes, elas adquirem suas aptidões realizando partos por conta própria ou após aprender o ofício com outras parteiras. 0 aprendizado, portanto, ocorre na prática, num contexto de falta de assistência às mulheres da comunidade em que a parteira atua. Em sua maioria, as parteiras são movidas por um desejo de servir, por um sentimento de solidariedade, pela necessidade de trabalhar.

Como começaram a fazer partos? Por quê? Suas respostas mostram que apesar das diferenças e dos locais distantes em que moram, a maioria partilha o início comum:
"Fuiparteira no susto. Não tinha outra. Tive que ir lá fazer" (Girassol).

Ou então

"Minha avó era parteira. Ela estava pra longe, lá pros lados do Curau quando uma prima nossa começou o serviço (trabalho de parto). Como eu era jeitosa, e acompanhava a vovó, me chamarame eu fui" (Gérbera).

Histórias que vão e voltam numa incansável repetição: são todas mulheres que atenderam aos apelos de outras mulheres. Às vezes ficavam horrorizadas com o que viam, quase em pânico, querendo recusar, mas não tinham saída, porque um parto no interior é, sobretudo, uma emergência (Tabela 1$)^{3}$.

Tabela 1: Distribuição das parteiras tradicionais

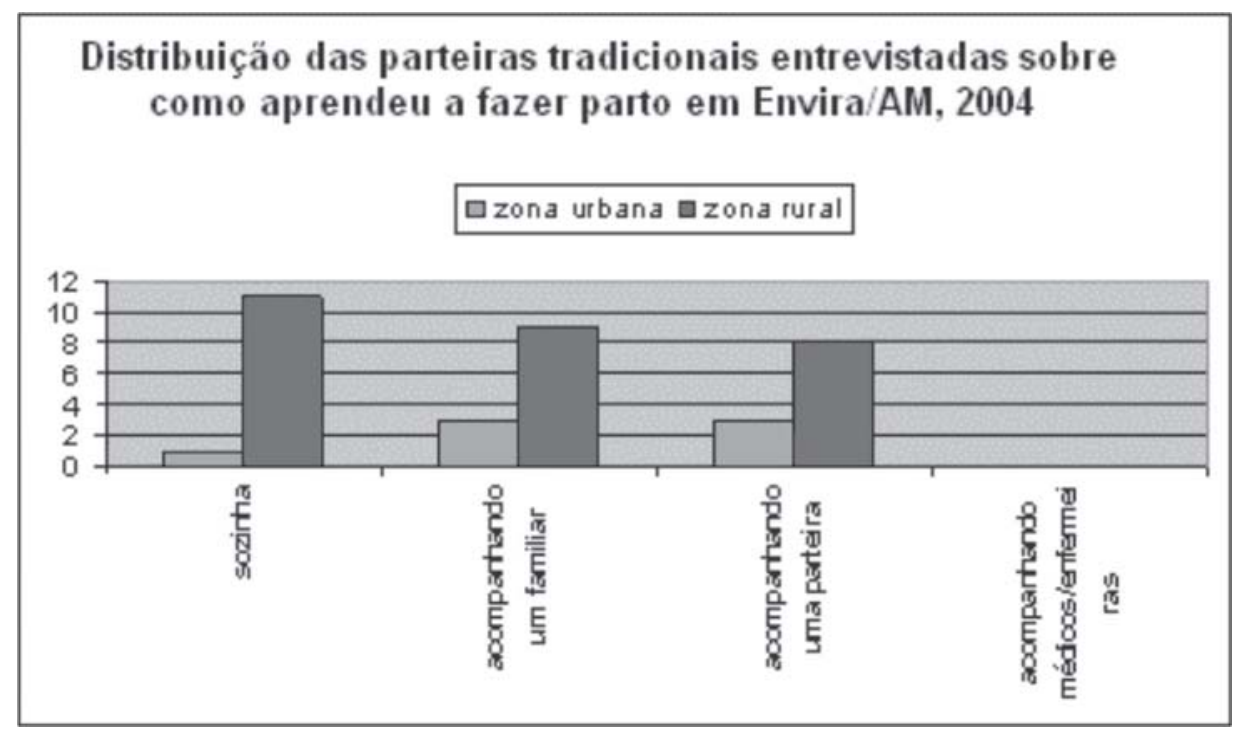

Fonte: ficha de entrevista. Envira, 2004.

Nada parece indicar que o aprendizado do ofício aconteça de forma hereditária: uma boa parte das parteiras são mulheres viúvas ou mesmo casadas. Supõe-se certa vocação para o oficio. Algumas mulheres, ao desempenhar esse ofício, o fazem em desacordo com a família ou com o marido ${ }^{6}$.

Um fato que chama a atenção é o conhecimento, que, muitas vezes, passa através da avó, e não da mãe. Também intrigante é o número de parteiras que aprendem sozinhas, muitas delas fazendo seus próprios partos sem ajuda de ninguém. Girassol conta que teve seu parto dessa maneira e que

[...] ]o pessoal disse: a comadre tem coragem. Aí, quando tem gestante, me chamam.

A coragem é um atributo essencial no ofício dessas mulheres. Elas não têm para onde fugir e nem a quem recorrer em caso de partos complicados. Somente elas e Deus, como costumam dizer. Orquídea fala que sua mãe já estava muito velha então pediam que ela acompanhasse a fim de lhe dar coragem. E nesse acompanhamento aprendeu os segredos de partejar.
CATEGORIA 3 - Partejar - quanto vale esse "dom": Questionadas sobre o recebimento em favor do trabalho de parteiras, verificamos que $20,6 \%$ recebem algum tipo de recompensa, sendo esta recompensa um presente $(57,1 \%)$ ou pagamento pela gestante $(42,9 \%)$, enquanto $79,4 \%$ afirmam não receber nada em troca, como diz Lírio:

a gente faz o serviço por vocação, por amor também, ninguém dá nada pra gente não.

Muitas parteiras referiram com certa mágoa o nãoreconhecimento de seu trabalho. Como disse Rosa:

uns dão muito obrigado, outros dizem - a senhora quer ir embora, vamos embora.

Em pesquisa realizada sobre as parteiras de Santa Catarina, temos que esta tarefa era recompensada em espécie, sendo, 
ademais, vista como uma missão a ser cumprida, jamais negligenciada ${ }^{6}$.

Quanto vale um dom oferecido por Deus? Tradicionalmente, partejar é considerado um dom divino, e as parteiras se contentam com uma galinha ou frutas de lembrança. No entanto, algumas reivindicam um pagamento pelo seu "dom", que deverá ser reconhecido pelo SUS como assistência ao parto por parteira.

0 pagamento dos partos em casa é encaminhado aos municípios por meio do "PAB variável", o Plano de Assistência Básica que incentiva as ações de saúde do município. 0 dinheiro, no entanto, só chega às parteiras se a prefeitura fizer isso. Só alguns municípios, além do estado do Amapá, estão pagando às mulheres que fazem o parto. $A R \$ 13,75$ (treze reais e setenta e cinco centavos) o parto, seriam mais de $R \$ 5$ milhões anuais que poderiam chegar às parteiras ${ }^{12}$.

CATEGORIA 4 - Problemas enfrentados pela parteira: As parteiras foram até muito recentemente mulheres de grande prestígio nas comunidades. A prática desse ofício, que envolvia conhecimentos de manobras do parto e práticas rituais específicas, garantia-lhes um espaço de reconhecimento simbólico bastante grande. Embora esse ofício não fosse economicamente rentável, estava investido de grande prestígio social (Tabela 2$)^{6}$.

Tabela 2: Principais problemas enfrentados pelas parteiras tradicionais

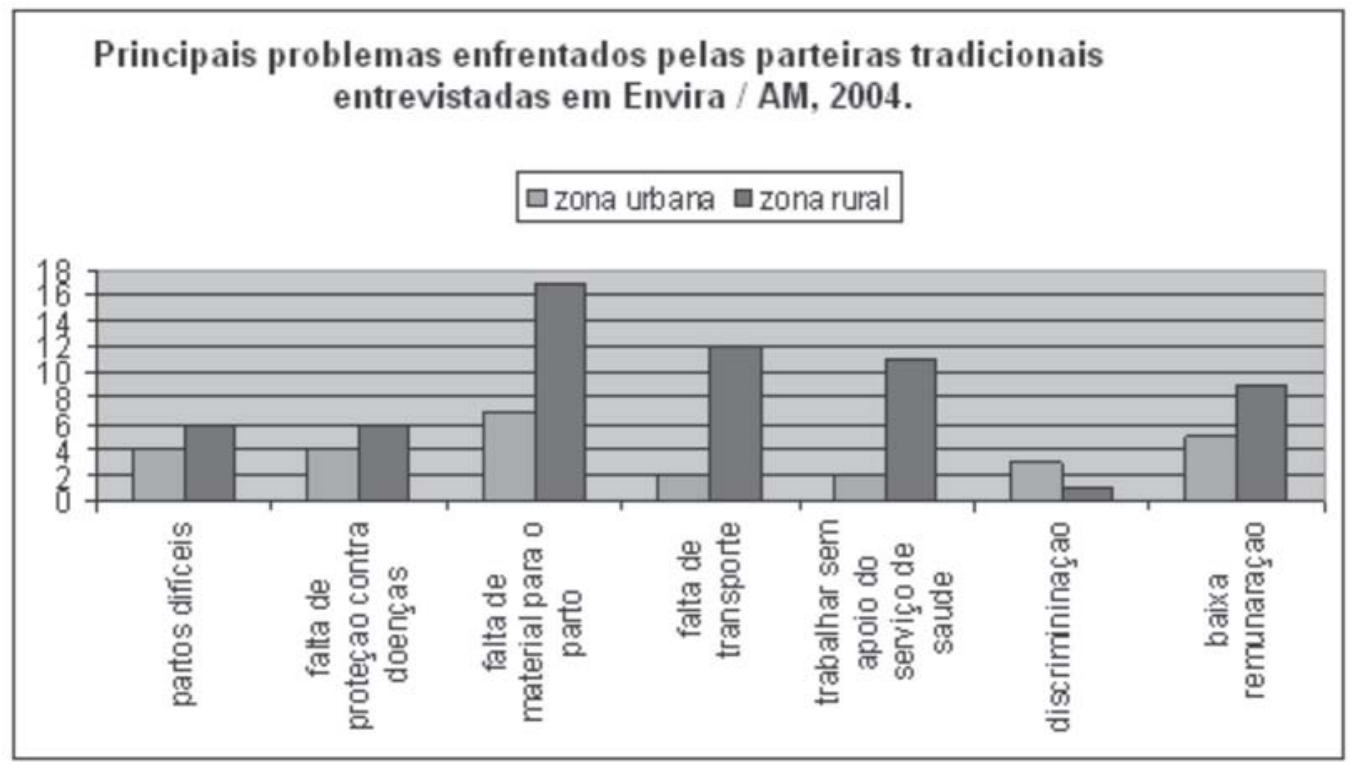

Fonte: ficha de entrevista. Envira, 2004.

Duas parteiras referiram como problema a pobreza da gestante. Durante a entrevista, Girassol conta de um parto que fez e precisou tirar sua saia para cobrir o bebe, pois a mãe não tinha nenhum pano para cobri-lo. Orquídea fala que, às vezes, as pessoas que ajuda não possuem nem "cueiro".

A falta de transporte é outro grave problema na zona rural, quando ficam em uma situação crítica: Se acontece um caso perigoso, como vou correr?

Tulipa nos conta que, ao fazer seu segundo parto, a criança morreu: mas foi falta de transporte para a cidade que não tinha. E o primeiro que nasceu foi a mão do bebê (Tulipa). Perguntando se ela não havia visto antes que a criança estava atravessada, ela disse que não, que a chamaram muito tarde:

Quando eu fui pra lá, já estava o bracinho pra fora, aínão tinha como eu virar. Mas nós fizemos já todos os apelos pra ela, pra ver se voltava aquele bracinho, mas não tinha jeito. Primeiro que aparecia era $o$ bracinho. Aí fomos atrás de uma baleeira aqui no Três bocas (nome do seringal), pra ver se a gente conseguia salvar ao menos a vida dela. Aímeu irmão conseguiu a baleeira e nós viemos embora, até chegar no Envira. De lá o Doutor fez cesárea. Nasceu morto, tudo quebradinho a cabeça, mas acho que devido ao choque da baleeira, que era um temporal bem forte; e duas vezes o rapaz meteu numa galhada e outro foi em cima de uma tora de pau, que caímos fora da baleeira. A senhora caiu pra dentro d'água, e ela o tempo todo nos gritos. Eu trouxe, que ainda teve esse rapaz que foi feliz. Chegamos lá era umas três horas da madrugada, que sofrimento. Foi um caso muito sério" (Tulipa).

Outros problemas enfatizados eram a falta de apoio do serviço de saúde e a falta de material para parto. Além de todas as dificuldades geográficas e de comunicação, as parteiras, em especial as do interior, ainda contavam com falta de tesoura, linha, panos, etc. Buscam resolver esse problema com reuniões sistemáticas e apoio dos Agentes Comunitários de Saúde da zona rural.

CATEGORIA 5 - Problemas frequentemente encontrados pelas parteiras na gestação/parto: Quando um parto é normal e a mulher é saudável, tudo vai bem. Mas quando há hemorragias, eclampsias, gravidez tubária, problemas 
cardíacos, má posição do feto, distância do hospital, ou a pobreza é muito grande, o trabalho da parteira se agrava. Partos difíceis, ou mesmo aqueles que tudo teriam para serem normais e que se agravam por anemias recorrentes, pedem mais do que solidariedade. Para enfrentar essas dificuldades, nem sempre as soluções empíricas e tradicionais funcionam, porque elas operam numa lógica de tempo, inclusive. E o custo disso são vidas perdidas e famílias desestruturadas, gerando uma sequência de novos problemas sociais e de saúde 4 .

Margarida conta por diversas vezes o mesmo fato ocorrido com uma gestante, que acabou morrendo após o parto. Parece que o fato de contar o episódio ajuda a minorar sua dor pelo acontecido, bem como poder escutar que não foi culpa sua o que se sucedeu. Foi o parto de sua prima que já estava na quarta gravidez e não poderia ter mais filhos. Nunca havia feito o pré-natal e negou-se a ter o bebê no hospital. Chamaram-na para acompanhar o parto sem ela saber de todos os problemas anteriores. A gestante teve placenta prévia e acabou morrendo no hospital. Pela forma como Margarida conta, a família deve ter lhe acusado pela morte da gestante (Tabela 3).

Tabela 3: Principais problemas na gestação e parto

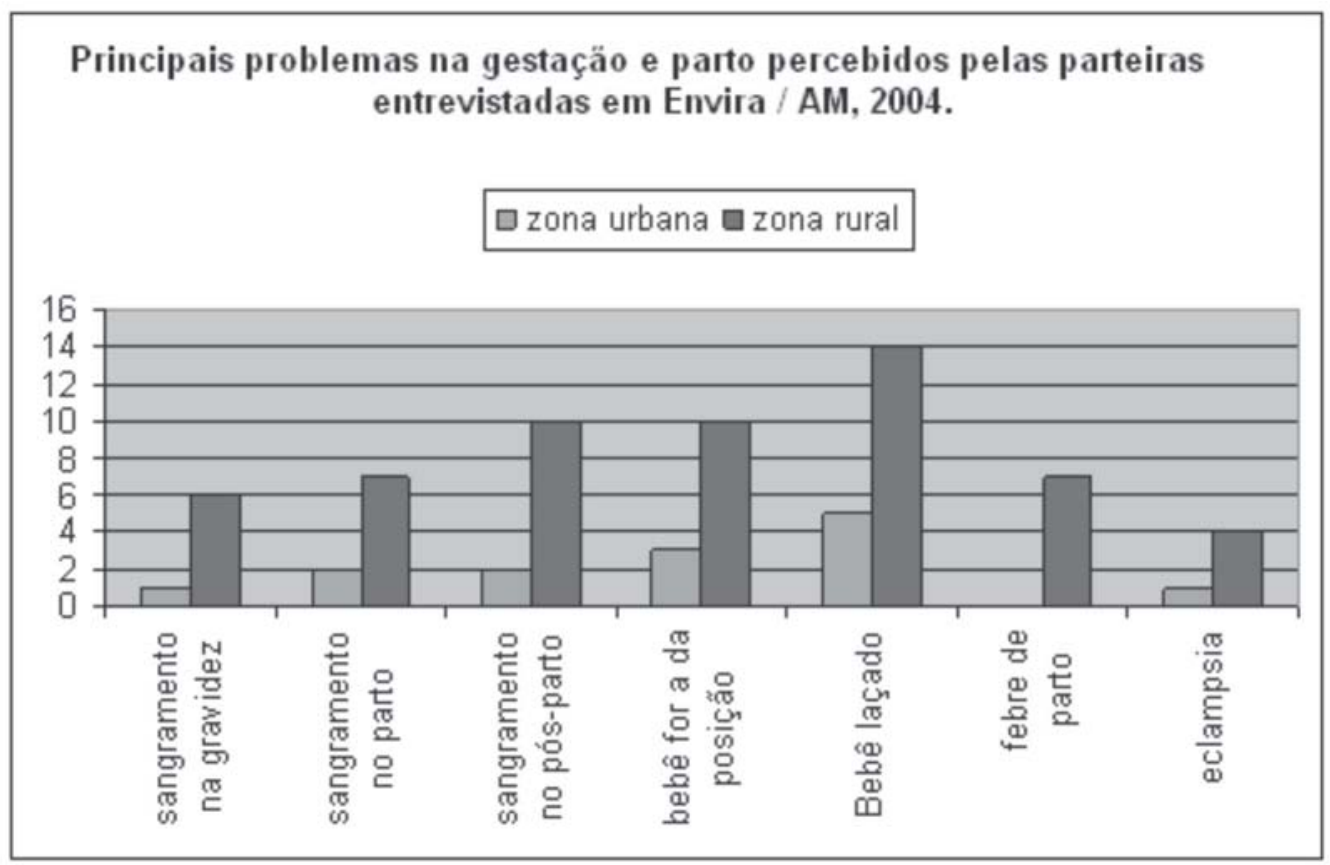

Fonte: ficha de entrevista. Envira, 2004.

Um dos problemas citados por Rosa é quando "ela não despacha logo", que significa que a mulher ficar muito tempo tendo contrações e o parto não acontece. Conta de um parto difícil:

foi o parto da minha nora, veio a criança de joelho, depois os braços. A cabeça demorou um pouco. Não chorou, estava todo roxo, achava que estava morto. Chupei no nariz, na boca. Já estava clareando o dia quando chorou. Custou pegar no peito, era todo diferente. Morreu com dois meses e cinco dias (Rosa).

Quase todas as parteiras têm histórias de partos difíceis, e como os resolveram. Lírio fala de um parto que fez e a criança estava de pé. Após o parto, já estava arrumando a criança e a vista da mãe escureceu, ela perdeu muito sangue. Deu chá de raiz do capim santo com raiz de chicória, só assim ela melhorou.

Mas talvez o fato mais intrigante fosse de um parto em que a parteira utilizou um anzol para puxar a criança. Ela já havia feito tudo o que conhecia para auxiliar o parto, mas a criança não descia. Aí colocou um anzol na cabeça da criança e foi puxando com cuidado, ate a criança descer. A criança hoje está grande, ficou apenas com algumas marcas na cabeça. Sempre que se conta esse caso, as pessoas ficam chocadas e costumam criticar a parteira. Mas aí é preciso pensar o que nós, profissionais técnicos de saúde, faríamos numa situação como essa, sem nenhum recurso, sem possibilidade de cesariana, sem tesoura para fazer episiotomia, sem anestesia, sem ocitocina ou outro medicamento que auxiliasse a induzir o parto. Como dizem, somente Deus para Ihe dar inspiração e ter alguma intuição que the ajude nessa hora.

CATEGORIA 6 - Relação com o serviço de saúde: informações retiradas do Consolidado do SIAB (Sistema de Informação da Atenção Básica), de Envira, mostram que existem no município 64 gestantes cadastradas, sendo 24 menores de 20 anos (37,5\%); 52 acompanhadas (81,25\%); 25 com vacinas em dia (39\%); 18 realizaram o pré-natal no mês $(28,1 \%)$; e somente 18 iniciaram o pré-natal no primeiro trimestre $(28,1 \%)$. Estes dados reforçam estatísticas gerais de saúde nas áreas rurais do País com baixos índices de prénatal, conforme a Tabela 4. 


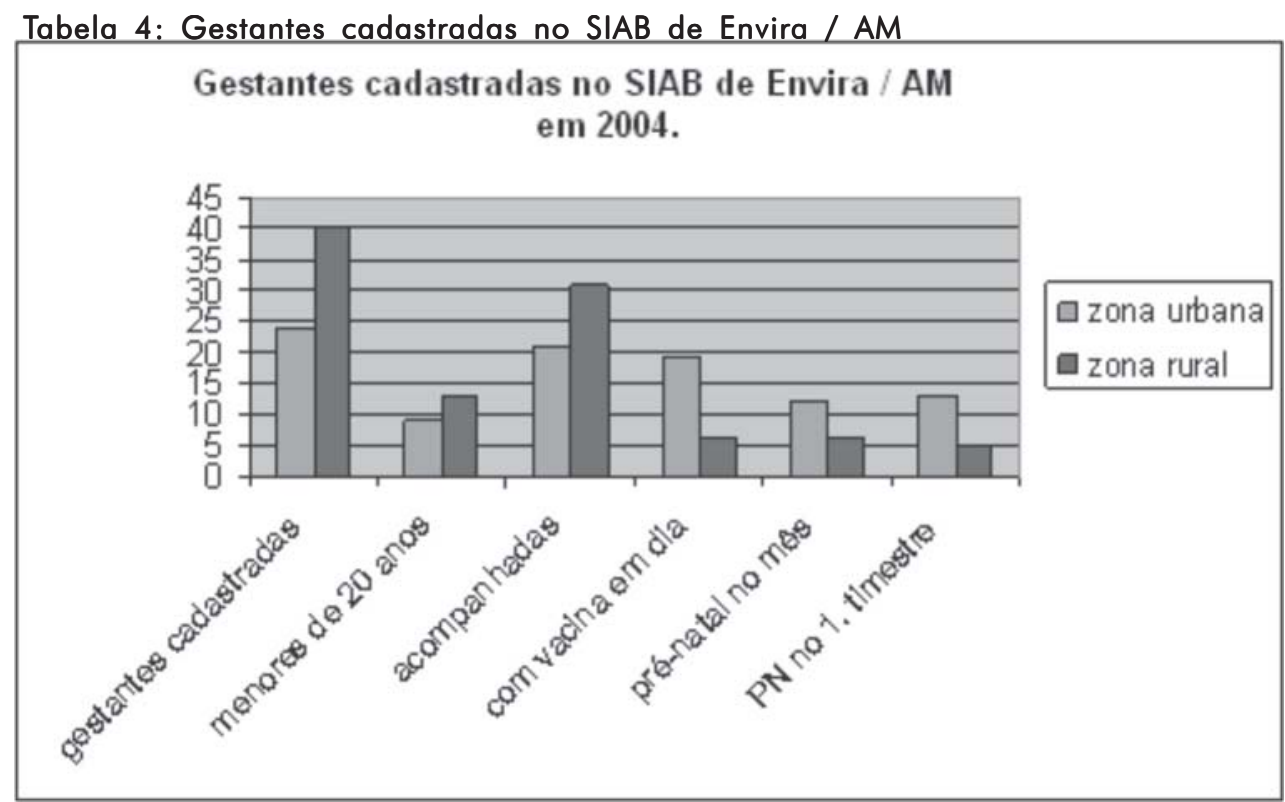

Fonte: SIAB. Envira, 2004.

Toda gestação trás em si mesma risco para a mãe ou para o feto. No entanto, um pequeno número delas tem esse risco muito aumentado, e é então incluído entre as chamadas gestações de alto risco. Desta forma, pode-se conceituar gravidez de alto risco aquela na qual a vida ou a saúde da mãe e/ou feto tem maiores chances de serem atingidas que as da média da população considerada ${ }^{8}$.

No Brasil, por suas grandes dimensões, e principalmente pelas diferenças socioeconômicas e culturais, evidenciam-se fatores de risco diversos para as várias regiões. Esses fatores geradores de risco podem ser agrupados em quatro grandes grupos, quais sejam: (1) características individuais e condições socioeconômicas desfavoráveis; (2) história reprodutiva da mulher anterior à gestação atual; (3) doenças obstétricas na gestação atual; (4) intercorrências clínicas?

Em Envira, os fatores de risco mais encontrados para as gestações encaixam-se especialmente nos três primeiros grupos e são: idade menor que 17 anos e maior que 35 anos; baixa escolaridade; peso menor que $45 \mathrm{~kg}$; morte perinatal; recémnascido com crescimento retardado; abortamento habitual; intervalo interpartal menor que dois anos e multiparidade.

Quanto às causas de morte materna, predominam as obstétricas diretas (74\%) e, entre essas, a eclampsia, a hemorragia, a infecção puerperal e 0 aborto. A maioria desses óbitos seria evitável mediante uma boa assistência de prénatal, parto e puerpério.

A despeito da dimensão criadora presente tanto nos partos quanto nas soluç̃oes encontradas para levá-los a bom termo, não se pode desconsiderar que mortes poderiam ser evitadas se houvesse prevenção eficiente ${ }^{3}$. Pois é justamente naquilo que poderia ser prevenido que reside o perigo: partos de mulheres que acumulam em suas vidas anemias, verminoses $e$ outras doenças nunca antes diagnosticadas ou tratadas. Rosa diz que começou a encaminhar as mulheres para o pré-natal após escutar um programa de rádio da pastoral na cidade vizinha.
Através dos relatos, observamos que, na maioria das vezes, a parteira atendia não só a mãe, mas também o recém-nascido, permanecendo vários dias junto a eles e acompanhando, assim, a evolução do pós-parto e do puerpério.

Durante o período de resguardo, a mulher ficava isenta de suas atividades domésticas habituais. Era comum que o marido, uma parenta ou mesmo a parteira permanecesse ali prestando auxilio na rotina doméstica, que ficava alterada no momento do pós-parto (quarentena). As parteiras, especialmente as que residem no interior, permaneciam na casa até cair o coto do umbigo da criança, podendo ser chamada para eventualidades no restabelecimento da mãe, a não ser quando a comunidade é muito distante. Hortênsia disse que fica até o final do resguardo. Quando tá em paz com a criança, aí para de acompanhar. Rosa refere que faz banho, acompanha tudo. Depois vai embora. Se a mulher não tem mãe, ela ajuda ainda mais.

0 pós-parto, contrariamente ao período da gravidez, era bastante significativo no sentido de demarcar o processo de retorno à vida cotidiana, o que sugere, também aqui, a existência de um ritual de retorno à vida alterada pelo evento do nascimento. Na quarentena, uma série de proibições e tabus relativos à alimentação, aos cuidados corporais e às relações sexuais era recomendada. As oposições do tipo frio/quente e seco/úmido permeiam vários desses cuidados. "Muita cautela e caldo de galinha" era a regra geral, embora não saibamos até que ponto fosse efetivamente observada por todas ${ }^{9}$.

A atenção sistemática ao ciclo gravídico-puerperal inclui, no mínimo, uma consulta pós-parto. Essa consulta éfundamental para a manutenção da amamentação, a introdução da contracepção necessária para o devido intervalo entre as gestações e a detecção de intercorrências próprias desse período.

Dados do Ministério da Saúde informam que, do total de mortes de crianças menores de um ano, $52 \%$ ocorrem no período neonatal (criança com menos de 28 dias de vida). $\mathrm{E}$ 
grande parte dessas mortes está associada, ainda, à baixa qualidade da assistência à gestação, ao parto e ao puerpério ${ }^{7}$.

\section{CONSIDERAÇÕES FINAIS}

A parteira tradicional do município de Envira é uma mulher madura, de baixa escolaridade e que já teve filhos. Pela importância de seu trabalho, tem um lugar reconhecido e respeitado na comunidade. Em geral, é identificada como líder, constituindo-se uma referência para a atenção à saúde da mulher e da criança. Muitas, além de cuidar dos numerosos filhos, trabalham na lavoura e pescam para completar a alimentação. Em sua maioria, não recebem nenhuma capacitação, ganham pouco ou quase nada pelo que fazem, não dispõem de materiais básicos para a realização do parto domiciliar e não tem apoio dos serviços de saúde. Não raro, os profissionais de saúde têm uma atitude preconceituosa e de resistência em relação às parteiras. Em muitas regiões do país, especialmente nas zonas rurais, ribeirinhas e lugares mais distantes, a única opção que existe para a mulher é o parto domiciliar realizado pelas parteiras tradicionais.

Essas grandes mulheres lutam pela vida, defendendo novas vidas, e servem de exemplo àqueles que não acreditam mais que é possível alguém fazer algo por outro alguém sem receber nada em troca, recompensa ou salário.

Fazer partos é tido como um dos trabalhos mais bonitos e emocionantes. Um "dom" que as parteiras possuem". Entretanto, parece paradoxal quando se constata que o trabalho da parteira leiga - que é feito de altas doses de solidariedade - revela exatamente o contrário disso: 0 abandono da mulher grávida pelo sistema de saúde. Utilizar os serviços da parteira não é uma opção por um modo de parir tradicional: é o efeito da falta de alternativas, pois lá as mulheres grávidas não têm escolhas. Dezenas de depoimentos falam do sofrimento vivido pelas mulheres pobres que habitam essas regiões distantes onde as pequenas chances de sobreviver a uma gravidez ou parto de risco são minoradas apenas quando conseguem sair a tempo atrás do socorro.

0 que assistimos no interior, principalmente nas regiões Norte, Nordeste e Amazônica são partos realizados nas residências pobres, insalubres e miseráveis de milhares de mulheres que moram em áreas longínquas, sendo atendidas por mulheres fortes, de boa vontade, mas muitas vezes despreparadas ou sem recursos para tal função.

Seria ingênuo acreditar que se possa reduzir o risco de óbito materno no Brasil, aos níveis observados hoje em países desenvolvidos, sem que ocorra uma substancial melhoria das condições de vida da população. Sabemos, no entanto, que centenas dessas mortes podem ser hoje evitadas se as autoridades de saúde fizerem o que está ao seu alcance para oferecer às gestantes o melhor atendimento possível.

A problemática da parteira tradicional insere-se, portanto, no quadro da saúde pública e sanitária. Uma maneira de minimizar os problemas respeitando as práticas consagradas pelo uso pode ser a adoção de processos integrais que privilegiem as abordagens sistemáticas de várias questões relativas à saúde e ao controle sanitário. Isso pode ser feito por meio da formação de parteiras tradicionais. Ainda que seja fundamental ter parteiras treinadas, é preciso que o poder público participe, mantendo postos de saúde com equipamentos e pessoal qualificado. Também é necessária uma ação técnica/ educacional forte e continuada, que leve em conta que, quando se tratam de conhecimentos tradicionais, há sempre uma via de mão dupla a ser considerada. É preciso manter aberto um canal de diálogo entre diferentes formas de pensamento científico. Assim como é essencial continuar com os treinamentos, também o é a manutenção da pesquisa e do registro de práticas de saúde desenvolvidas com eficácia por essas populações ao longo dos tempos ${ }^{3}$.

A consolidação da medicalização, viabilizada através da rede de atendimento materno-infantil nos anos 60, envolve dimensões bastante instigantes do ponto de vista teórico: marca a substituição de um ritual de passagem, tradicionalmente vivido no âmbito das comunidades, por um ritual institucionalizado e moderno ${ }^{5}$; além disso, marca a passagem de um saber popular para um saber médico.

A complexidade deste processo de mudança na arte de parturição tem relaç̃̃es com outras dimensões, para além daquelas do gênero e da classe. Modificações econômicas, sociais, bem como inovações científicas no campo da obstetrícia e aprofundamento no processo de valorização do bebê e do feto, tornam ainda mais complexo esse processo $0^{6}$. No entanto, se é evidente a estruturação de um novo habitatus no que tange ao parto em classes médias e populares, também são notáveis as propostas de re-humanização do parto, neste novo século. Sabe-se que há um longo caminho a percorrer na reversão dos quadros de doenças, pobreza e abandono. Um caminho no qual, as parteiras treinadas poderão desempenhar importante papel, na medida em que atingem muitas mulheres e se configuram como multiplicadores concretos de conhecimentos.

\section{Referências}

1.Ministério da Saúde (BR). Secretaria de Atenção à Saúde. Departamento de Ações Programáticas Estratégicas. Área Técnica de Saúde da Mulher. Relatório de Gestão 2003-2006. Brasilia (DF); 2006. Versão preliminar

2.Luzes EM. A necessidade do ensino da ciência do início da vida [tese de doutorado]. Rio de Janeiro (RJ): Instituto de Psicologia/ UFRJ; 2007.

3.Mascelani A. Parteiras do abandono: um mergulho no mundo das parteiras que atuam nas margens dos rios e igarapés da região amazônica de Caxiuanã e Melgaço. Belém (PA): Ed. Mauad; 2002.

4.Gualda DMR. Eu conheço minha natureza: a expressão cultural do parto. Curitiba (PR): Ed. Maio; 2002. 
5.Mamede FV, Mamede MV, Dotto LMG. Reflexões sobre deambulação e posição materna no trabalho de parto e parto. Esc Anna Nery Rev Enferm 2007; 11 (2): 331-36.

6.Tornquist CS. Parto e poder: o movimento pela humanização do parto no Brasil. [tese de doutorado]. Florianópolis (SC): PPGAS/ UFSC; 2004.

7.Ministério da Saúde (BR). Parto, aborto e puerpério: assistência humanizada à mulher. Brasília (DF); 2001 .

8.Ministério da Saúde (BR). Secretaria de Assistência à Saúde. Departamento de Promoção e Assistência à Saúde. Coordenação Materno Infantil. Diretrizes básicas de assistência ao parto domiciliar por parteiras tradicionais. Programa de Assistência Integral à Saúde da Mulher. Brasília (DF); 1994.
9.Melo N, Viana P. Gestação e parto. Recife (PE): Boletim Curumim; 2006.

10. Ministério da Saúde (BR). Conselho Nacional de Saúde. Resolução $n^{\circ} 196$, de 10 de outubro de 1996. Diretrizes e normas regulamentadoras de pesquisas envolvendo seres humanos. Inf Epidemiol SUS 1996; 5 (2 supl 3): 13-41.

11 - Bardin L. Análise de conteúdo. Tradução de Luís Antero Reto e Augusto Pinheiro. Lisboa (P0): Ed 70; 2002.

12 - Ministério da Saúde (BR) Secretaria de Atenção a Saúde. Melhoria da assistência ao parto domiciliar realizado por parteiras tradicionais. Brasília (DF); 2006. 